\title{
Three cases of ectopic sphenoid sinus pituitary adenoma
}

\author{
Ernest Jan Bobeff ${ }^{1}$, Karol Wiśniewski ${ }^{1}$, Wielisław Papierz ${ }^{2}$, Ludomir Stefańczyk ${ }^{3}$, Dariusz Jan Jaskólski ${ }^{1}$ \\ ${ }^{1}$ Department of Neurosurgery and Neuro-Oncology, Medical University of Lodz, Barlicki University Hospital, tódź, ${ }^{2}$ Institute \\ of Health Sciences, State School of Professional Education in Plock, Płock, ${ }^{3}$ Department of Radiology, Medical University of Lodz, \\ Barlicki University Hospital, tódź, Poland
}

\begin{abstract}
Introduction: Ectopic sphenoid sinus pituitary adenoma is a rare tumour originating from embryologic remnants of Rathke's pouch. Although it is considered a clinically benign neoplasm, necrosis is encountered in $25 \%$ of cases and it can invade adjacent bone structures.

Aims: To establish clinical, radiological and histopathological features of ectopic sphenoid sinus pituitary adenoma. Material and methods: Analysis of three cases: two females and one man, aged 61-70.

Results: One patient presented with a unilateral hearing loss, the other two with headache and vertigo. They all suffered from type 2 diabetes mellitus. Neurological examination revealed no abnormality. Radiological imaging showed a sphenoid sinus space-occupying soft-tissue lesion with bone erosion in 2 cases and empty sella in 2 patients whereas one had a normal pituitary gland. All were operated on via the transnasal approach. Total resection was achieved in one patient and subtotal in two; in two cases we observed intact sellar dura and in one intact sellar floor. Histopathology showed immunoreactivity for synaptophysin in all cases and cytokeratin in two. The Ki-67 index was less than 2\%. Immunohistochemical staining demonstrated growth hormone cells in all cases whereas prolactin and adrenocorticotropin in two. The patients were discharged home in good condition with no neurological deficits.

Conclusions: Ectopic sphenoid sinus pituitary adenoma should always be considered in differential diagnosis of sphenoid sinus lesion in the elderly, especially in coexistence with empty sella or type 2 diabetes mellitus. Since ectopic sphenoid sinus pituitary adenoma is a benign lesion, surgical removal is an effective treatment.
\end{abstract}

Key words: sphenoid sinus, empty sella, neuroendocrine markers, plurihormonal, ectopic pituitary adenoma.

\section{Introduction}

Pituitary adenoma (PA) is a common entity in the sellar region, it accounts for approximately $12 \%$ of primary brain tumours [16]. Its ectopic localization in sphenoid sinus is seen in $0.48 \%$ of cases [17]. Although ectopic sphenoid sinus pituitary adenomas (ESSPAs) are benign neoplasms, necrosis is encountered in $25 \%$ of them [17]. They are either characterized by well-defined radiological margins $[17,19]$ or described as bone invading expansile lesions $[4,15]$. They originate from embryologic remnants of Rathke's pouch, which prematurely terminated their migration to the pituitary fossa $[2,4,10,15,17,19]$.

\footnotetext{
Communicating author:

Ernest Jan Bobeff, Department of Neurosurgery and Neuro-Oncology, Medical University of Lodz, Barlicki University Hospital, 22 Kopcińskiego St., 90-153 tódź, Poland, phone: +48 4267767 70, e-mail: ernestbobeff@gmail.com
} 


\section{Material and methods}

In order to reveal clinical, radiological and histopathological features of ESSPA, we analysed three cases: two females and one male, aged 61-70.

\section{Results}

Patient 1, a 64-year-old-female, presented with a unilateral left-sided insidious hearing loss of one year's duration. Her medical history was notable for mild hypertension (HT) and type 2 diabetes mellitus (DM II). Additionally she had a past medical history of hypothyroidism, glaucoma, and menopause at the age of 25 . The radiological imaging showed a spaceoccupying soft-tissue lesion within the sphenoid sinus protruding into the left choana (Fig. 1). It had irregular enhancement after gadolinium administra- tion. Empty sella and bone erosion were observed (Fig. 2). The sella turcica was slightly deepened, lined with a $2 \mathrm{~mm}$ thick strand of the pituitary gland and the narrowed pituitary stalk. We performed a subtotal resection of the tumour via the transnasal approach. It presented as a necrotic mass, tender in consistency and with blurred margins. Despite the erosion of adjacent bone structures including sellar floor, it was possible to recognise the intact sellar dura. She was discharged home in good condition with no neurological deficits.

Patient 2, a 70-year-old woman, was referred for evaluation of a $2-\mathrm{cm}$ heterogeneous sphenoid sinus mass discovered when a magnetic resonance scan was obtained to evaluate H/A and vertigo. She offered no other complaints. She had a past medical history of DM II and HT treated medically. On mag-

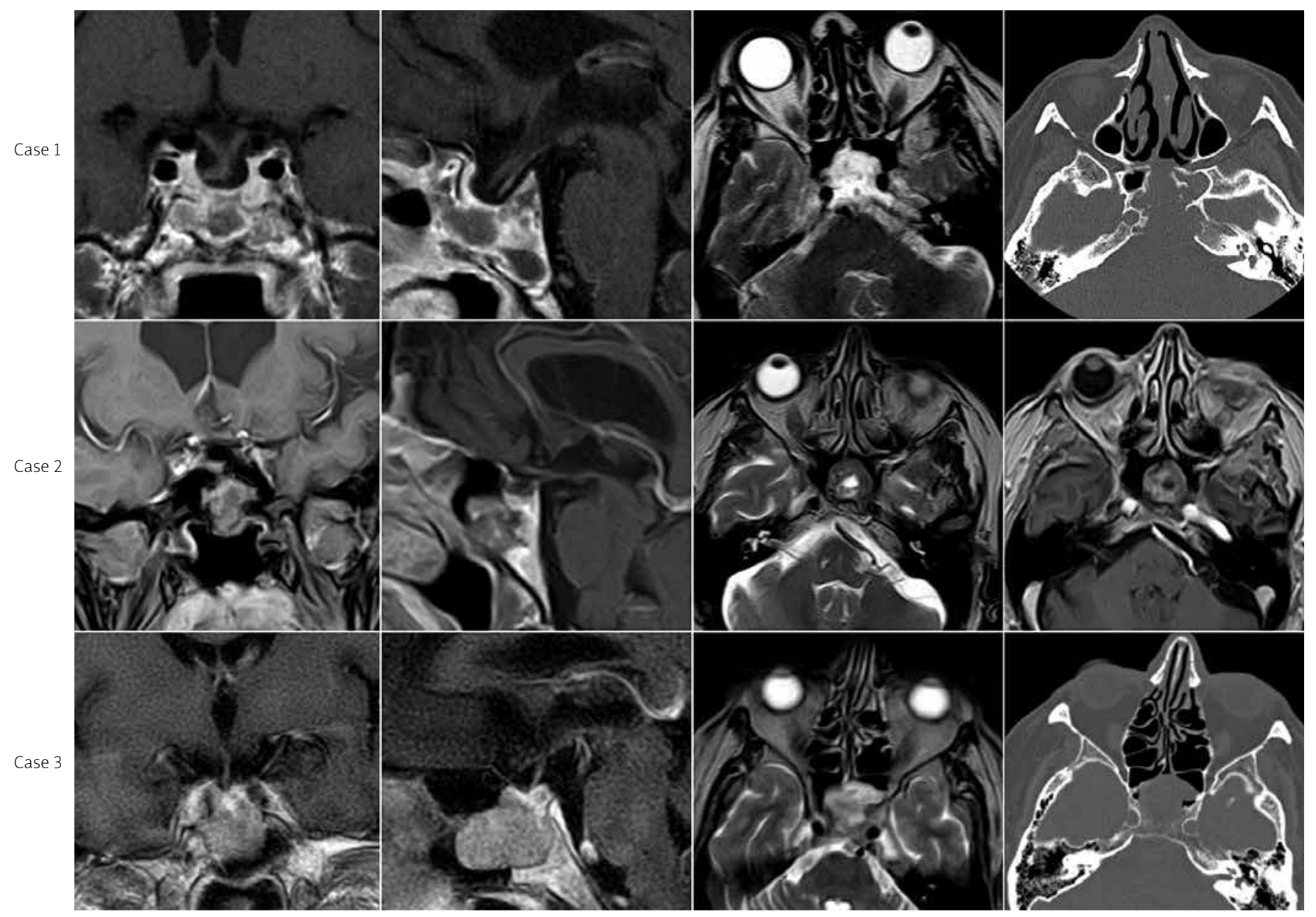

Fig. 1. Post-gadolinium T1-weighted (coronal and midline sagittal) and T2-weighted (axial) MR images of three cases of ectopic sphenoid sinus pituitary adenoma before surgery - column 1-3; CT scans showing bone erosion in patients 1 and 3, and post-gadolinium T1-weighted axial MR image of case 2 (column 4). 

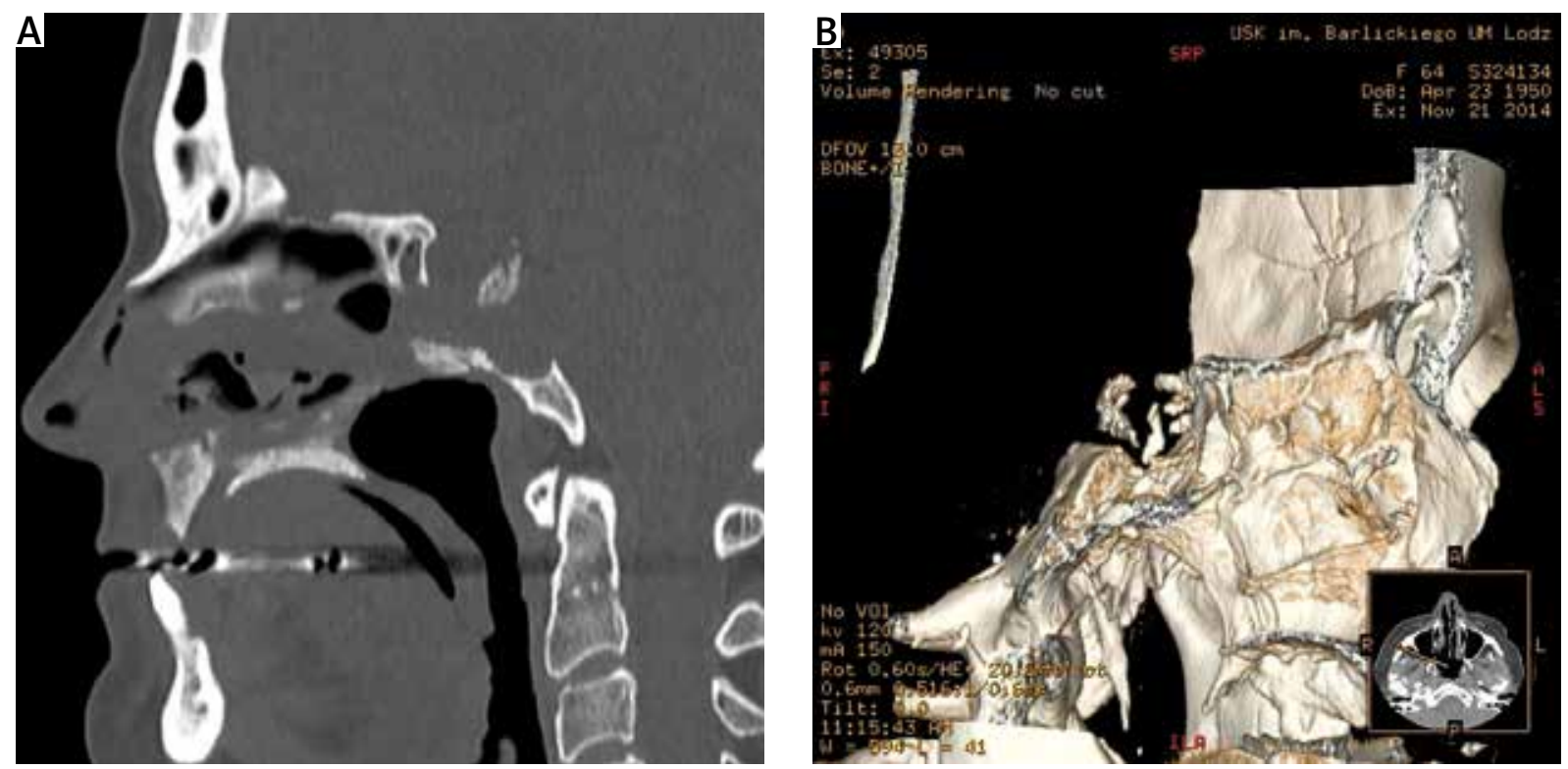

Fig. 2. Computed tomography midline sagittal scan showing bone erosion in patient 1 (A); 3D reconstruction (B).

netic resonance (MR) images after administration of gadolinium enhancement, we observed an irregular soft-tissue lesion within the sphenoid sinus, with a liquid cyst located interiorly (Fig. 1). It had welldefined margins and there was a normal pituitary gland located inside the sella turcica. She was operated on via the transnasal approach and the lesion was totally removed. The bone borders of the sphenoid sinus were confirmed intact. She was discharged home in good condition with no neurological deficits.

Patient 3, a 61-year-old man, was referred to the neurology clinic for evaluation of chronic H/A and episodes of vertigo. He had modest comorbidities such as mild HT and DM II, well-controlled with medications. Radiological studies revealed a space-occupying soft-tissue lesion within the sphenoid sinus with increased bone turnover, and suspected empty sella (Fig. 1). After gadolinium administration it had regular enhancement. The patient was operated on via the transnasal approach; we performed a subtotal resection of the lesion. The intact sellar dura was confirmed. He was discharged home in good condition with no neurological deficits.

The initial histopathological examination showed small fragments of tissue with alternating mucoid and fibrous, hyalinized stroma in all cases (Fig. 3). The tumours consisted of small, monomorphic cells with hyperchromatic nuclei and scant cytoplasm.
In the first case, necrosis was found in the central zone. The neoplastic cells were arranged in nests and separated by thin-walled vessels and poorly vascularized connective tissue. Haemorrhage was focally observed. All tumours showed no cytologic features of malignancy, with the Ki-67 labelling index of less than $2 \%$ and no mitotic figures. Immunohistochemical staining for the transcription termination factor and CD68 were negative in all cases, while cytokeratin was positive in the second and third case. Immunoreactivity for neuroendocrine markers including synaptophysin, neuron-specific enolase, chromogranin A and CD56 was observed. In the first case, the tumour demonstrated some S100-positive cells. The above immunophenotypes indicated a neuroendocrine tumour without cytologic features of malignancy and suggested a differential diagnosis between pituitary adenoma and paraganglioma. We performed immunohistochemical staining for pituitary hormones, which demonstrated growth hormone $(\mathrm{GH})$ cells in all cases whereas prolactin (PRL) and adrenocorticotropic hormone (ACTH) in two. Hence, the final diagnoses of pituitary adenoma were established.

In the first case, hormone tests revealed a slightly increased prolactin level. The patients remain under surveillance for further growth symptoms by MRI and were referred to an endocrinologist for medical treatment. 


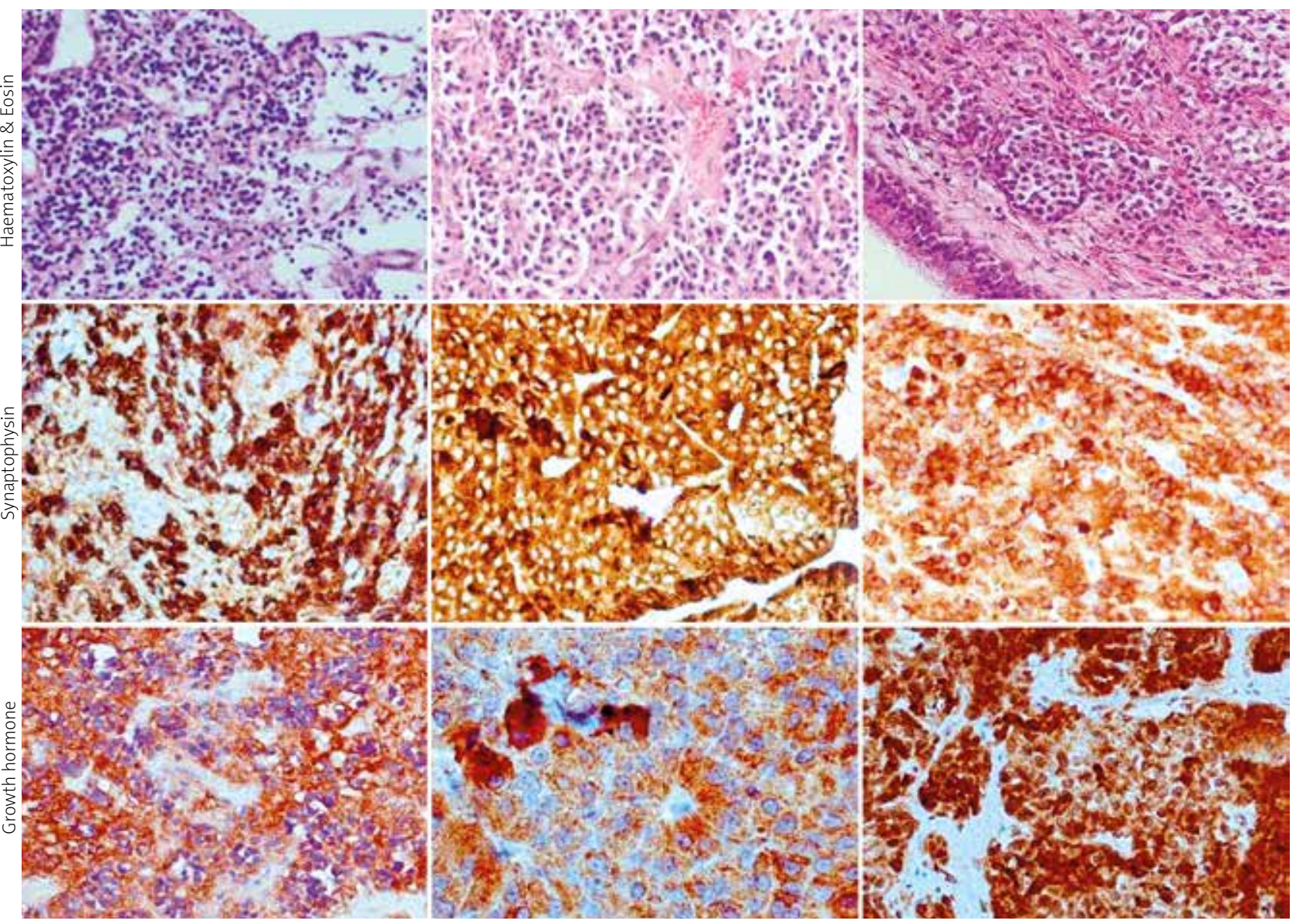

Fig. 3. The initial histopathological examination with haematoxylin and eosin (line 1); immunoreactivity for synaptophysin (line 2); immunohistochemical staining for pituitary hormones demonstrating growth hormone cells in all cases (line 3).

\section{Discussion}

The pathogenesis of ectopic pituitary adenoma (EPA) is not fully understood. It is hypothesized that neoplastic transformation occurs within the ectopic pituitary tissue located along the path of migration of Rathke's pouch, that is in the craniopharyngeal canal, or in the adjacent area $[2,4,10,15,17,19]$. Most frequently this tissue may be found in the sphenoid sinus, and then is called 'ectopic intrasphenoid hypophysis' $[7,18]$. Consequently, the coexistence with the primary empty sella in such cases results from premature termination of migration of Rathke's pouch, before reaching the pituitary fossa $[4,10,15,19]$. As it was shown in a recent review by Liang et al. [10] (Table I), to date only 15 cases of ESSPA associated with an empty sella have been reported in the literature $[2,4-6,9-12,19]$.
The largest series of ESSPA in the literature by Thompson et al. included 32 cases [17] (Table I). The authors revealed that the mean age of diagnosis was greater than in typical pituitary adenoma by approximately 10 years. They indicated most sensitive neuroendocrine markers that are synaptophysin and CD56, which were also positive in our study.

Ectopic sphenoid sinus pituitary adenomas encompasses a wide range of symptomatology: acromegaly, Cushing's syndrome, sexual dysfunction, amenorrhea, MEN-1 syndrome (multiple endocrine neoplasia type 1), nasal obstruction, rhinorrhoea and epistaxis, H/A, vertigo, and ear symptoms such as hearing loss. All those although mentioned in the literature, can hardly be related to a lesion limited to the sphenoid sinus. We are of the opinion that also in our series the tumours were incidental findings. 
Table I. Results of the study and review of the literature

\begin{tabular}{|c|c|c|c|c|c|}
\hline Factor & Case 1 & Case 2 & Case 3 & Thompson et al. 2012 [16] & Liang et al. 2014 [10] \\
\hline Sex & Female & Female & Male & 16 males, 16 females & $\begin{array}{c}4 \text { males, } 6 \text { females, } \\
5 \text { unknown }\end{array}$ \\
\hline Age & 64 & 70 & 61 & Mean age 57.1 & Unknown \\
\hline Clinical summary & $\begin{array}{c}\text { Unilateral } \\
\text { hearing loss, } \\
\text { DM II, HT }\end{array}$ & $\begin{array}{c}\mathrm{H} / \mathrm{A} \text { and } \\
\text { vertigo, DM } \\
\text { II, HT }\end{array}$ & $\begin{array}{c}\mathrm{H} / \mathrm{A} \text { and } \\
\text { vertigo, DM } \\
\text { II, HT }\end{array}$ & $\begin{array}{c}\text { Asymptomatic H/A } \\
\text { Chronic sinusitis } \\
\text { Obstructive symptoms } \\
\text { Visual disturbances } \\
\text { Mass } \\
\text { Nerve changes } \\
\text { Balance or hirsutism }\end{array}$ & $\begin{array}{c}\text { Acromegaly } \\
\text { Cushing's syndrome } \\
\text { Sexual dysfunction } \\
\text { Amenorrhea } \\
\text { MEN-1 syndrome } \\
\text { Nasal obstruction } \\
\text { Rhinorrhoea \& epistaxis } \\
\text { Unilateral hearing loss }\end{array}$ \\
\hline \multicolumn{6}{|l|}{ Imaging studies } \\
\hline Empty sella & + & - & + & - & $100 \%(15 / 15)$ \\
\hline Bone involvement & + & - & + & $66 \%(21 / 32)$ & Unknown \\
\hline Intact sellar dura & + & + & + & Unknown & $87 \%(13 / 15)$ \\
\hline Intact sellar floor & - & + & - & Unknown & Unknown \\
\hline Size & $32 \mathrm{~mm}$ & $20 \mathrm{~mm}$ & $28 \mathrm{~mm}$ & Mean size $34 \mathrm{~mm}$ & Unknown \\
\hline Resection & Subtotal & Total & Subtotal & Unknown & Unknown \\
\hline \multicolumn{6}{|l|}{ Pathology } \\
\hline Necrosis & + & - & - & $25 \%(8 / 32)$ & Unknown \\
\hline $\mathrm{PRL}$ & + & + & - & $59 \%(13 / 22)$ & $4 / 9$ \\
\hline $\mathrm{ACTH}$ & + & - & + & $33 \%(6 / 18)$ & $1 / 9$ \\
\hline $\mathrm{GH}$ & + & + & + & $26 \%(5 / 19)$ & $3 / 9$ \\
\hline $\mathrm{TSH}$ & - & - & - & $29 \%(5 / 17)$ & Unknown \\
\hline FSH & - & - & - & $47 \%(9 / 19)$ & Unknown \\
\hline Synaptophysin & + & + & + & $97 \%(29 / 30)$ & Unknown \\
\hline Neuron-specific enolase & + & + & + & $76 \%(13 / 17)$ & Unknown \\
\hline Chromogranin A & + & + & + & $71 \%(17 / 24)$ & Unknown \\
\hline CD56 & + & + & + & $91 \%(10 / 11)$ & Unknown \\
\hline $\mathrm{S} 100$ & + & - & - & $7 \%(1 / 15)$ & Unknown \\
\hline Pan-cytokeratin & - & + & + & $79 \%(22 / 28)$ & Unknown \\
\hline Ki-67 & $<1 \%$ & $<1 \%$ & $<2 \%$ & All $<3 \%$ & Unknown \\
\hline Hormone tests & Slightly $\uparrow P R L$ & Normal & Normal & & \\
\hline
\end{tabular}

Regarding the differential diagnosis, invasive pituitary adenoma is an important consideration. Initial intrasellar localization of a pituitary adenoma with a following localized or diffuse destruction of sellar floor and extension into the sphenoid sinus - grade 3 and 4 in modified Hardy's system - is expected in $35 \%$ and $10 \%$ of cases, respectively [13]. Although MRI may help to confirm the integrity of sellar dura and sellar floor $[4,10,12,19]$, the gold standard is an intraoperative verification [2,5,6,9-11,15]. In case of bone erosion of sphenoid, the evidence of ESSPA seems less justifiable. In our series, computed tomography (CT) scans demonstrated erosion of the sellar floor in two patients, with preserved integrity of dural lining on MRI which was later confirmed on surgery. In one case (patient 2), the sphenoid bone was intact.

In the first case, a slightly increased prolactin concentration was observed, possibly related to the empty sella, rather than to the secreting nature of the tumour. Hyperprolactinaemia is seen in $21 \%$ of ESSPA [17] and in 15\% of the empty sella syndromes [1]. Some authors suggest it is due to the stalk effect observed in the intrasellar hypertension and consists of impaired dopamine delivery [1,3]. Continuity of the pituitary stalk is essential for adequate development and well-functioning of the pituitary gland [8]. We inferred that the process of developing adenoma in 

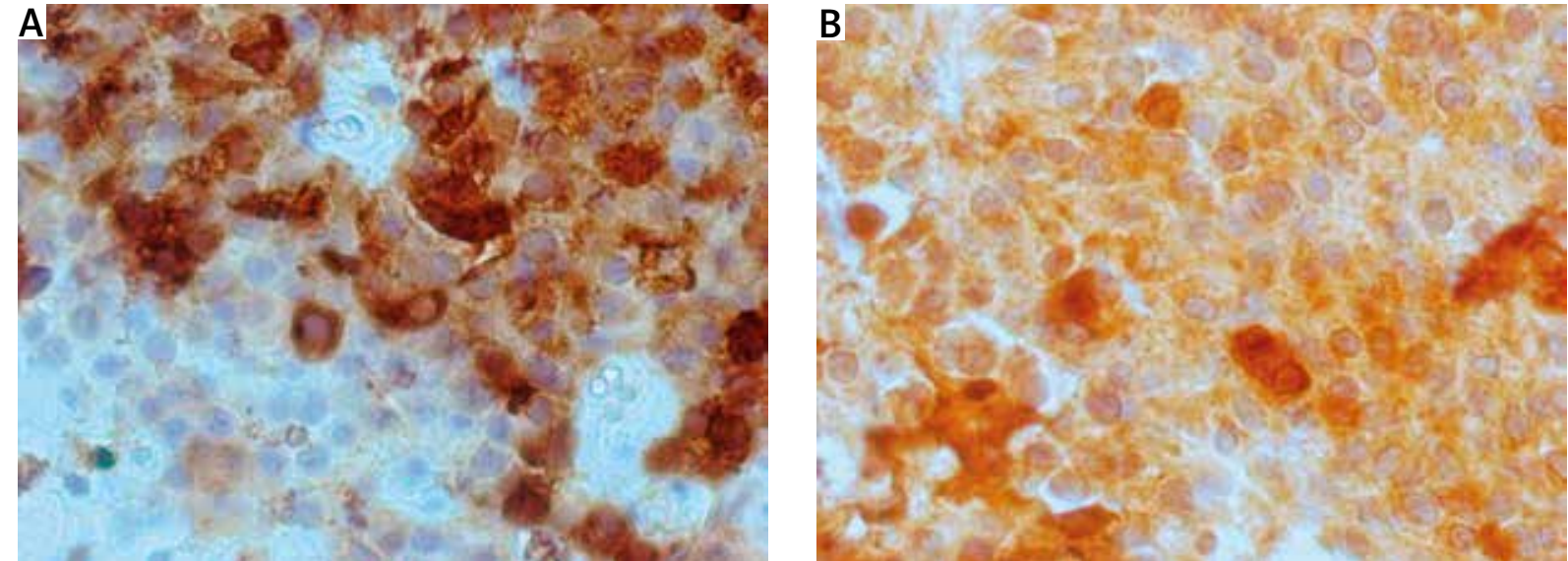

Fig. 4. Plurimorphous pituitary adenoma observed in patient 3: immunohistochemical staining revealed positive reaction for adrenocorticotropic hormone (A) and growth hormone (B) cells.

the ectopic pituitary gland may be a direct corollary of lack of the hypothalamic regulation of pituitary development during embryogenesis and subsequent impaired dopamine delivery.

A significant proportion of PA is plurihormonal. Plurimorphous PA, however, defined as showing more than one cell type, is a very rare entity [14]. In our study, we observed 2 cases (patient 1 and 3) of non-functioning PA, which were simultaneously locally positive for both ACTH and GH (Fig. 4).

Currently, there is no established treatment for ESSPA [2]. Thompson et al. postulated that surgical removal is a treatment of choice independently of hormone test results [17]. Preoperative medical therapy may be considered in prolactin-secreting pituitary adenomas as it can effectively reduce the size of the tumour. Additional characteristics that might support the conservative treatment are lack of symptoms (incidental finding) and elderly age of a patient.

Ectopic sphenoid sinus pituitary adenoma is a rare tumour that should always be considered in differential diagnosis of a sphenoid sinus lesion in the elderly, especially in coexistence with empty sella, DM II and HT. It can be commonly characterised by radiological and histopathological features of invasiveness - bone erosion and necrosis - despite its clinically benign nature. Surgical confirmation of the intact sellar floor or sellar dura is required to differentiate ESSPA from invasive PA. Surgical removal is an effective treatment.

\section{Disclosure}

Authors report no conflict of interest.

\section{References}

1. Agarwal JK, Sahay RK, Bhadada SK, Reddy V, Agarwal NK. Empty Sella syndrome. J Indian Acad Clin Med 2001; 2: 198-201.

2. Ajler P, Bendersky D, Hem S, Campero A. Ectopic prolactinoma within the sphenoidal sinus associated with empty sella. Surg Neurol Int 2012; 3: 260-263.

3. Bergsneider M, Mirsadraei L, Yong WH, Salamon N, Linetsky M, Wang MB, MCArthur DL, Heaney AP. The pituitary stalk effect: is it a passing phenomenon? I Neurooncol 2014; 117: 477-484.

4. Das CJ, Seith A, Gamanagatti S, Goswami R. On the AJR viewbox. Ectopic pituitary adenoma with an empty sella. AJR Am J Roentgenol 2006; 186: 1468-1469.

5. Gondim JA, Schops M, Ferreira E, Bulcão T, Mota JI, Silveira C. Acromegaly due to an ectopic pituitary adenoma in the sphenoid sinus. Acta Radiol 2004; 45: 689-691.

6. Hong J, Ding X, Wang S. Coexistence of ectopic pituitary adenoma and empty sella in a patient with acromegaly: a case report and review of literature. Neurol India 2012; 60: 304-306.

7. Jinkins JR. Atlas of Neuroradiologic Embryology, Anatomy, and Variants. LWW, Philadelphia 2000.

8. Kelberman D, Rizzoti K, Lovell-Badge R, Robinson IC, Dattani MT. Genetic Regulation of Pituitary Gland Development in Human and Mouse. Endocr Rev 2009; 30: 790-829.

9. Kusano Y, Horiuchi T, Oya F, Miyaoka Y, Oguchi K, Takemae T, Hongo K. Ectopic pituitary adenoma associated with an empty sella: a case report and review of the literature. J Neuroimaging 2013; 23: 135-136.

10. Liang J, Libien J, Kunam V, Shao C, Rao C. Ectopic pituitary adenoma associated with an empty sella presenting with hearing loss: case report with literature review. Clin Neuropathol 2014; 33: 197-202.

11. Matsuno A, Katayama H, Okazaki R, Toriumi M, Tanaka H, Akashi M, Tanaka K, Murakami M, Tanaka H, Nagashima T. Ectopic pituitary adenoma in the sphenoid sinus causing acromegaly associated with empty sella. ANZ J Surg 2001; 71: 495498. 
12. Naswa N, Das CJ, Sharma P, Karunanithi S, Bal C, Kumar R. Ectopic pituitary adenoma with empty sella in the setting of MEN-1 syndrome: detection with 68Ga-DOTANOC PET/CT. Jpn J Radiol 2012; 30: 783-786.

13. Oruçkaptan HH, Senmevsim O, Ozcan OE, Ozgen T. Pituitary adenomas: results of 684 surgically treated patients and review of the literature. Surg Neurol 2000; 53: 211-219.

14. Rasul FT, Jaunmuktane Z, Khan AA, Phadke R, Powell M. Plurihormonal pituitary adenoma with concomitant adrenocorticotropic hormone (ACTH) and growth hormone (GH) secretion: a report of two cases and review of the literature. Acta Neurochir 2014; 156: 141-146.

15. Slonim SM, Haykal HA, Cushing GW, Freidberg SR, Lee AK. MRI appearances of an ectopic pituitary adenoma: case report and review of the literature. Neuroradiology 1993; 35: 546-548.

16. Thapar K, Kovacs K, Scheithauer BW, Lloyd RV. Diagnosis and Management of Pituitary Tumors. Humana Press, Totowa 2001

17. Thompson LD, Seethala RR, Müller S. Ectopic Sphenoid Sinus Pituitary Adenoma (ESSPA) with Normal Anterior Pituitary Gland: A Clinicopathologic and Immunophenotypic Study of 32 Cases with a Comprehensive Review of the English Literature. Head Neck Pathol 2012; 6: 75-100.

18. Tortori-Donati P, Rossi A. Pediatric Neuroradiology - Brain. Head, Neck and Spine. Springer, New York 2005.

19. Yang BT, Chong VF, Wang ZC, Xian JF, Chen QH. Sphenoid sinus ectopic pituitary adenomas: CT and MRI findings. Br J Radio 2010; 83: 218-224. 